Article

\title{
Exploring the Relationship between Perceived Ease of Use and Continuance Usage of a Mobile Terminal: Mobility as a Moderator
}

\author{
Aoshuang $\mathrm{Li}^{1,2, *}$, Yongqiang Sun ${ }^{3, *}$, Xiaodong Yang ${ }^{1} \mathbb{C}$ and Jinyu Guo ${ }^{1}$ \\ 1 School of Management, Harbin Institute of Technology, Harbin 150001, China; yangxd@hit.edu.cn (X.Y.); \\ 1991guojniyu@163.com (J.G.) \\ 2 School of Information Management, Heilongjiang University, Harbin 150080, China \\ 3 School of Information Management, Wuhan University, Wuhan 430072, China \\ * Correspondence: Correspondence: las8027@126.com (A.L.); sunyq@whu.edu.cn (Y.S.)
}

Received: 15 January 2019; Accepted: 19 February 2019; Published: 21 February 2019

\begin{abstract}
As the number of mobile terminal users has increased worldwide, research on continuance usage of a mobile terminal (CUMT) has received wide attention to facilitate the sustainability of development of mobile application providers. However, different results of the relationship between perceived ease of use (PEU) and continuance usage toward information technology were found in prior studies, and studies that mainly focus on their linear relationship cannot provide an explanation of the different results. The purpose of this study was to explore the relationship between PEU and CUMT to examine the intriguing possibility that a curvilinear relationship can be found. This study proposed a model with a moderator of mobility based on the environment-behavior relationship theory and expectation disconfirmation theory. The research model was tested with 311 respondents collected in China through hierarchical regressions method. The results empirically indicate that mobility moderates the relationship between PEU and CUMT and show a linear relationship under high levels of mobility and a U-shaped relationship under low levels of mobility. At a low PEU stage, PEU negatively and significantly influences the behavior of CUMT, while, at a high PEU stage, there is a positive relationship between PEU and CUMT. This paper provides a detailed explanation of this behavior in the mobile Internet context. This paper discusses theoretical contributions and practical implications for the sustainable development of mobile application providers as well as the limitations of the study and future research directions.
\end{abstract}

Keywords: continuance usage of a mobile terminal; curvilinear relationship; expectation disconfirmation; mobility; perceived ease of use; sustainable development

\section{Introduction}

Many users worldwide use mobile terminals daily, and continuance usage of a mobile terminal (CUMU) has become a part of their routine lives [1,2]. Mobile applications have advantages over traditional methods (e.g., convenience, mobility, and entertainment). The various mobile applications installed in a mobile terminal can provide a variety of functions to meet users' multiple needs, thus users are willing to use mobile applications for various activities anywhere and anytime, such as information search, communication, and payment [3]. Using mobile applications through a mobile terminal is more beneficial to users than before. Additionally, users are important for mobile application providers in a competitive market, and the cost of finding a new user is greater than the cost of keeping an old one [4], thus CUMT is important for mobile application providers to sustain development [5-7]. Therefore, this study explored CUMT to understand user behavior to promote sustainable development 
of mobile application providers. CUMT refers to users' continual use of a mobile terminal for mobile applications over a long period after adoption [8,9].

As Bhattacherjee [8] (pp. 351-352) noted, "the long-term viability of an IS and its eventual success depend on its continued use"; continuance usage (CU) plays a critical role in an information system (IS) sustainability [7]. The literature contributes to the knowledge on the CU of IS [7,8,10-15]. Most CU studies are conducted based on technology acceptance models (TAM) $[8,14,16,17]$. The viewpoint of the studies based on TAM deems that perceived usefulness (PU) and perceived ease of use (PEU) are key factors influencing attitude and intention toward technology acceptance or IS usage behavior [17-21].

However, different explanations for PU and PEU on the CU are found in existing studies. Existing works provide consistent evidence that PU is a determinant of CU [21-24], but some studies also show inconsistent results regarding the relationship between PEU and CU. For example, some studies confirm that PEU significantly impacts CU [14,24-26], while others suggest that PEU ceases to be important after the adoption of the IS or a mobile application [16,27-29]. Thereby, we believe the relationship between PEU and CU might be complex-i.e., it could be nonlinear.

Existing research on the PEU-CU relationship generally focuses on linear studies to explore the significant and causal relationship, neglecting the curvilinear relationship. In many disciplines such as management, psychology and, especially, economics, some empirical studies identify and explore nonlinear relationships, such as U-shape and inverted U-shape [30-33]. Because nonlinear relationships can describe how relationships change in different stages during the whole process, they are important for providing complex explanations of some phenomena [30-33]. Therefore, this study explored whether there is a curvilinear relationship between PEU and CU. In the mobile Internet context, PEU is important for different users to use mobile applications because mobile applications provide more functions and information through mobile terminals with a small screen [34]. Thus, the first research question was proposed:

RQ1: Is there a curvilinear relationship between PEU and CUMT?

Further, mobility plays a key role for users to continue to use mobile terminals [25,35]. Mobility refers to the degree to which users conveniently access the mobile Internet, regardless of time and place [36]. With the continued development of mobile technology, mobility is omnipresent worldwide; it enhances connections among users and facilitates the usage of mobile terminals [36-38]. However, there are different levels of mobility worldwide, even in the same country or city [39]. Because different levels of mobility can form different usage environments that are related to CUMT behavior [40], the influence of mobility on CUMT might be different under different levels of mobility. To our knowledge, there are insufficient studies on the relationship of PEU on CUMT under different levels of mobility. Therefore, we also explored the moderating effect of mobility on the relationship between PEU and CUMT so that we can provide a clearer explanation for CUMT behavior to promote mobile application providers sustainability. The second research question was proposed as follows:

RQ2: Does mobility moderate the curvilinear relationship between PEU and CUMT?

To answer these questions, we carried out this study based on the environment-behavior relationship theory and expectation disconfirmation theory. The former theory, which stems from environmental psychology, can explain some phenomena regarding the relation of human behavior with the environment at different levels [40]. The point of view of the latter is that consumer decisions on repeat behavior are associated with satisfaction or dissatisfaction that is the result of a comparison between expectation and actual perception [41-44]: "Essentially, the disconfirmation paradigm is based on a cognitive process" [44] (p. 131). We believe these theories are appropriate to answer these research questions because: (1) the behavior of CUMT occurs in the mobile Internet context and the usage environment of mobile terminals plays a core role in the process of CUMT; and (2) the user internal cognition also acts as a major role in this process. This study contributes to the CU and mobility literature, enriches curvilinear research on $\mathrm{CU}$, and extends the application of environment-behavior relationship theory and expectation disconfirmation theory in the mobile Internet context. 
The remainder of this paper is organized as follows. In Section 2, after exploring the theoretical background, we propose research hypotheses and advance a research model. In the Section 3, the design of the questionnaire and survey is described and an appropriate analytical approach for the current hypotheses test is provided. In the Section 4 , after evaluating the reliability and validity of the scale, we test the current hypotheses by using hierarchical regressions and provide the empirical results. Finally, we discuss theoretical contributions and practical implications to promote the sustainable development of mobile application providers.

\section{Theoretical Background and Hypotheses}

\subsection{The Relationship between PEU and $\mathrm{CU}$}

Prior studies on $\mathrm{CU}$ are consistent with the viewpoint that $\mathrm{CU}$ is important for IS sustainability $[7,8,14,24,25]$, and plenty of CU studies are based on the TAM model, which suggests that PU and PEU are key factors influencing the behavior of technology acceptance and adoption of IS $[18,19,21,26]$. However, evidence from empirical research shows that these two variables play different roles in CU studies. PU is still considered as an important construct to explain CU and a significant effect is consistently reported in some empirical studies [14,24,45]. Other CU studies based on TAM only introduce PU into the research model, ignoring PEU. Even if both PU and PEU were introduced into the CU model, inconsistent results of PEU on CU are found in empirical studies. For example, Thong (2006) [14] incorporated PU, PEU, and perceived enjoyment into an expanded expectation-confirmation model and suggested that PEU significantly influences the CU intention of mobile Internet services and that "the nature of the IT can be an important boundary condition in understanding the continued IT usage behavior" (p. 799). Cho (2016) [24] showed that PEU has a significant relationship with the intention of the CU of health apps on smartphones. In multiple stage empirical studies, Karahanna et al. (1999) [16] suggested that PEU was not important for the CU of Windows technology at the post adoption stage. Joo et al. (2016) [45] confirmed that PEU had no significant effect on the $\mathrm{CU}$ of a mobile learning management system. More interesting, a study on the CU of mobile financial services (MFS) shows that PEU is one of the factors influencing continued usage in MFS. In that study, when gender is taken as the moderator, the results show that PEU has a significant impact on CU for females but is insignificant for males [25]. Table 1 shows a summary of inconsistent results for the relationship between PEU and CU. We believe these inconsistent results might be caused by the curvilinear relationship between variables. To our knowledge, there are no studies on the curvilinear relationship of PEU with CU.

Table 1. Summary of the significance of PEU on CUMT.

\begin{tabular}{|c|c|c|c|}
\hline Author and Years & PEU-CUMT & Path Coefficient & Research Setting \\
\hline Thong, Hong, and Tam, 2006 & sig & $0.20 * * *$ & mobile Internet services \\
\hline M.-C. Lee, 2010 & sig & $0.211^{* *}$ (attitude) & e-Learning \\
\hline Cho, 2016 & sig & $0.25 * * *$ & health apps on smartphones \\
\hline Hsieh, Chen, and Hung, 2015 & $\begin{array}{l}\text { sig } \\
\text { sig }\end{array}$ & $\begin{array}{l}0.240 * \\
0.311 *\end{array}$ & \multirow[t]{2}{*}{ electronic portfolio } \\
\hline \multirow{3}{*}{ Yen and $\mathrm{Wu}, 2016$} & sig & $0.240 *$ & \\
\hline & sig & $0.562 * *$ (for females) & \multirow[t]{2}{*}{ mobile financial services } \\
\hline & ns & 0.093 (for males) & \\
\hline Joo, Kim, and Kim, 2016 & ns & -0.190 & \multirow{4}{*}{$\begin{array}{l}\text { a mobile learning } \\
\text { management system } \\
\text { e-Learning } \\
\text { mobile banking } \\
\text { integrated accounting and } \\
\text { budgeting software }\end{array}$} \\
\hline Islam, 2011 & ns & 0.04 & \\
\hline Yuan, Liu, and Yao, 2016 & ns & -0.07 & \\
\hline Halilovic and Cicic, 2013 & ns & -0.02 & \\
\hline Karahanna, Straub, and & sig & $0.06^{\mathrm{a}}$ (pre-adoption) & \multirow{2}{*}{ windows technology } \\
\hline Chervany, 1999 & ns & 0.21 (post-adoption) & \\
\hline
\end{tabular}


Table 1. Cont.

\begin{tabular}{clll}
\hline \multicolumn{1}{c}{ Author and Years } & PEU-CUMT & Path Coefficient & Research Setting \\
\hline \multirow{2}{*}{ Mou, Shin, and Cohen, 2017 } & sig & $0.140 *$ (pre-usage) & online health information \\
& ns & 0.080 (post-usage phases) & services \\
\hline
\end{tabular}

Notes: sig, significance; ns, no significance; ${ }^{*} \mathrm{p}<0.5 ;{ }^{* *} \mathrm{p}<0.01 ;{ }^{* * *} \mathrm{p}<0.001 ;{ }^{\mathrm{a}} \mathrm{p}<0.1$; CUMT, continuance usage of a mobile terminal; PEU, perceived ease of use.

\subsection{The Importance of PEU}

In the mobile Internet context, various mobile applications are widely applying with new features such as mobility and conveniences [46]. Research on the CU of mobile applications including mobile Internet services, mobile financial services and health apps on smartphones has received wide attention $[14,24,25]$. With the large-scale usage of mobile terminals, which can install various mobile applications, this popular method to complete tasks is replacing traditional ways [24,25,47]. CUMT is crucial for the sustainable development of mobile applications. Mobile applications with different aims provide various functions and contents to meet users' needs including information search, communication, location, payment and backstage services $[2,47,48]$. However, the size of a mobile terminal is usually small, especially in regard to smartphones, which limits the information display and operation toward mobile applications [34]. Additionally, the configuration of different types of mobile terminals are different, such as the memory and central processing unit, which leads to different operating speeds of mobile applications. If a mobile application provides features with more ease of use, it may fit various types of mobile terminals. Moreover, among large-scale users of mobile terminals, it is necessary to take users' ages into account. For example, many elderly users require simpler steps to successfully access information [24,46]. Thus, PEU is important for users to employ mobile applications in the mobile Internet context. According to the argument above, we think that the concern of the construct of PEU is more interesting while exploring the CUMT. In this study, PEU was operationally defined as users' perceptions of the degree of ease in using mobile applications through a mobile terminal $[18,47]$.

\subsection{Mobility as a Moderator of the Relationship between PEU and CUMT}

Existing studies usually consider mobility as a factor that influences user behavior of $\mathrm{CU}$ and mainly focus on linear relationship studies $[35,49,50]$. However, mobility is different in different places, even in the same city [39]. According to environment-behavior relationship theory, different levels of mobility can constitute different usage environments in which different users' internal cognitions are aroused, causing different behavior modes [40]. PEU is used to depict users' beliefs regarding using mobile applications, reflecting users' cognition toward CUMT behavior [18]. The effect of PEU on the behaviors of CUMT might be different under different levels of mobility. Therefore, in this study, mobility is considered as a moderator of the relationship between PEU and CUMT.

Under low levels of mobility, users cannot access the mobile Internet to use mobile applications easily, and they only use some mobile applications at some points in space and time [39]. According to environment-behavior relationship theory, because low levels of mobility frequently obstruct users' successful acquisition of information or complete tasks via the mobile Internet, usage behaviors are often limited. This behavior constraint disturbs users' cognition of the mobile terminal [40]. When users become aware that they are losing perceived control of mobile application usage, negative emotions such as unpleasantness and disappointment often result. Meanwhile, according to expectation disconfirmation theory, before actual usage of a mobile terminal, there is an expectation of using mobile terminals in user internal cognition. Different levels of PEU mean there are different perceptions of actual usage. Divergences between expectations and different levels of PEU will lead to user satisfaction or dissatisfaction related to the behavior of using mobile terminals [41-43].

On the one hand, a low level of PEU means that the PEU could not satisfy users' needs because of an unfriendly interface, unclear interaction or other factors. When actual PEU cannot 
meet users' expectations, the divergence between expectations and low levels of PEU leads to users' dissatisfaction [41-43]. Because users have experienced negative emotions with low levels of mobility, when users fall into uncomfortable states, they usually exaggerate the divergence [41,51]. Under this condition, even if the level of PEU shows some improvement, the negative emotion is dominant in user cognition, and users gradually lessen the behavior of CUMT. Prior studies confirm that user dissatisfaction decreases the subsequent behavior, such as re-purchase and re-use [42,43]. As such, low levels of PEU negatively and significantly influence CUMT under low levels of mobility.

On the other hand, as environment-behavior relationship theory suggests, when the internal state is full of negative emotion, users feel a deviation from their internal most comfortable state so that they display a tendency to change the state to achieve the comfortable state by methods such as exploration, perception, and adjustment [40]. Thus, once PEU reaches a certain level that can match their expectations, the divergence between expectation and PEU disappears and, in turn, when levels of PEU are beyond user expectations, users' satisfaction appears. When a positive emotion forms in users' internal cognition, users enhance that satisfactory state, which is enough to overcome the negative emotion caused by low levels of mobility [41,51]. Under such a condition, the positive emotion is dominant in user cognition, and users turn to enhancing the usage of mobile terminals to satisfy themselves more [42,43]. As the level of PEU increases in the high PEU stage, users are more satisfied with mobile applications, and their internal cognition tends to their best comfortable state [40]. Consequently, high levels of PEU positively enhance the behavior of CUMT under low levels of mobility. Therefore, the following hypothesis was proposed:

H1: There is a U-shaped relationship between PEU and CUMT under low levels of mobility.

A high level of mobility benefits the creation of a steady environment of using mobile terminals in which users can access mobile applications without limitations of space and time [36,37]. According to environment-behavior relationship theory, as one of the steady factors of usage environment, mobility has little influence on the behavior of CUMT or user cognition [40]. When there is divergence between expectation and actual PEU, users can obtain enough information or support to use mobility applications with high levels of mobility so that perception of actual usage can easily meet or exceed user expectations. Under such a condition, positive satisfaction is dominant in user cognition. As the level of PEU increases, users are willing to use mobile applications to achieve their purposes, such as seeking information, ordering, and shopping [52]. In their leisure time in particular, users will unconsciously employ mobile applications through mobile terminals to entertain themselves or pass the time, such as by reading news from websites, minding a friend's circle in an instant message, or playing mobile phone games [53]. Hence, PEU enhances the behavior of CUMT. Prior studies confirm that PEU positively and significantly influences the CU of mobile applications $[14,24]$. Therefore, there is a linear PEU-CUMT relationship under high levels of mobility. For these reasons, the following hypothesis was proposed:

H2: PEU positively and significantly affects CUMT under high levels of mobility.

Summarizing the discussion above, we advance a model of CUMT (see Figure 1). In this model, PEU is introduced as the independent variable, CUMT as the dependent variable, and mobility as a moderator of the relationship between PEU and CUMT. We especially consider the curvilinear relationship in the moderating process to provide a more detailed explanation for PEU to CUMT.

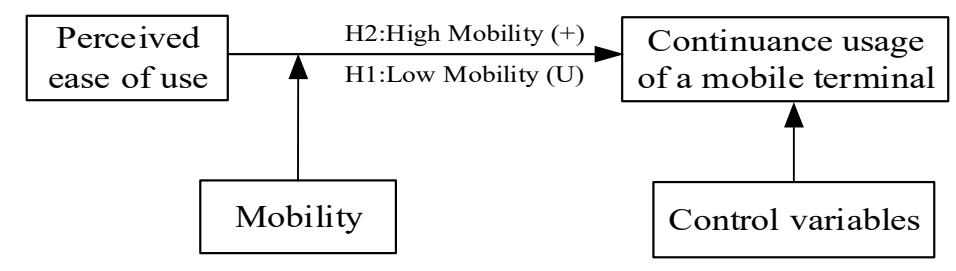

Figure 1. Research model. 


\section{Methods}

\subsection{Questionnaire Design}

This study used validated measures from previous research on IS and CU $[8,18,36]$ to measure the CUMT, PU, PEU, and mobility. The measurement of CUMT was adapted from Bhattacherjee (2001) [8], the measures of PU and PEU are adapted from Davis et al. (1989) [18], and the measurement of mobility was adapted from Nikou and Bouwman (2014) [36]. Each measurement included 3-4 items, and the measurement scales are shown in Appendix A. Prior studies on IS and CU consider demographic characteristics such as the gender, age, experience, and frequency with net as potential controls [54,55]. According to the use characteristics of mobile terminal users, this study selected four demographic characteristics as control variables: gender, age, education level, and total time of daily use of a mobile terminal. Additionally, because studies based on TAM always consider PU as an important determinant that influenced the behavior of $\mathrm{CU}$ and the explanatory power of $\mathrm{PU}$ is stronger than PEU, PU was also introduced as a control variable [19-21].

We created an initial questionnaire in English, which was then translated into Chinese. To ensure content consistency and validity, the double-blind translation of the questionnaire was conducted with the help of three bilingual scholars in the IS field. We corrected the questionnaire based on their comments, and then carried out a pre-survey among fifty college students to evaluate the reliability and validity of the questionnaire. Based on the results, the survey questionnaire was finalized, which was based on a five-point Likert scale: strongly disagree, disagree, neutral, agree and strongly agree.

\subsection{Data Collection}

The data were randomly collected using a cross-sectional survey of mobile terminal users in China. In total, 500 questionnaires were distributed, of which 405 were received. We excluded some questionnaires that included same answers, contradictory answers, or missing answers. The number of remaining questionnaires was 311 . The effective rate of the response was $62.2 \%$. The proportion of male respondents was slightly higher than that of female respondents, accounting for $54.3 \%$ of the total; the main age group was between 20 and 39, accounting for $84.6 \%$; the main education level was undergraduate, accounting for $69.8 \%$; and the most frequent total time of daily use was $1-3 \mathrm{~h}$, accounting for $53.3 \%$.

\subsection{Analytical Approach}

Ping suggested that it is beneficial to estimating the coefficients of interaction terms to apply the method of hierarchical regressions [56] and that the test of curvilinear relationships, including interaction terms and squared terms, is always conducted using this method [30,32,57]. This study tested the moderating effect and curvilinear relationship proposed in the research hypotheses that include interaction terms and squared terms. According to prior studies on the curvilinear relationship, we believe the hierarchical regression method is appropriate to test the current research model.

\section{Results}

\subsection{The Reliability and Validity Test}

To evaluate the reliability and validity of the scale, a test using SPSS 19.0 was conducted. Because factor loading of PU3 was 0.61, which was lower than others, we deleted PU3 to ensure good reliability and validity, and then conducted the test again. As shown in Table 2, each composite reliability (CR) was greater than 0.80 , far above the recommended threshold of 0.60 ; each average variance extracted (AVE) was greater than 0.60 , above the suggested value of 0.50 ; and each Cronbach's alphas was greater than 0.70. Further, each factor loading was greater than 0.60 (see Table 3), showing that reliability was good [58]. Table 3 also shows that each item was loaded on corresponding construct, suggesting good convergent validity [58]. Additionally, discriminant validity was evaluated by comparing the 
square root values of the AVE. As shown in Table 4, the correlations were lower than the square root values of the AVE in the last four diagonal cells, indicating that discriminant validity was met [58]. The evaluations of reliability and validity sufficiently supported examining the hypotheses of the structural model.

Table 2. Results of reliability.

\begin{tabular}{lllllll}
\hline \multicolumn{1}{c}{ Variables } & Items & Mean & SD & Cronbach's $\alpha$ & CR & AVE \\
\hline CUMT & 4 & 4.35 & 0.04 & 0.88 & 0.87 & 0.63 \\
PEU & 4 & 4.39 & 0.03 & 0.85 & 0.84 & 0.61 \\
MOB & 3 & 3.95 & 0.05 & 0.82 & 0.86 & 0.68 \\
PU & 3 & 4.35 & 0.03 & 0.79 & 0.82 & 0.60 \\
\hline
\end{tabular}

Notes: SD, standard deviation; CR, composite reliability; AVE, average variance extracted; CUMT, continuance usage of a mobile terminal; PEU, perceived ease of use; MOB, mobility; PU, perceived usefulness.

Table 3. Factor loadings.

\begin{tabular}{lllll}
\hline & $\mathbf{1}$ & $\mathbf{2}$ & $\mathbf{3}$ & $\mathbf{4}$ \\
\hline CUMT1 & $\mathbf{0 . 8 2}$ & 0.22 & 0.13 & 0.22 \\
CUMT2 & $\mathbf{0 . 8 3}$ & 0.16 & 0.16 & 0.16 \\
CUMT3 & $\mathbf{0 . 8 3}$ & 0.14 & 0.18 & 0.17 \\
CUMT4 & $\mathbf{0 . 6 9}$ & 0.31 & 0.13 & 0.25 \\
PEU1 & 0.18 & $\mathbf{0 . 7 4}$ & 0.15 & 0.24 \\
PEU2 & 0.12 & $\mathbf{0 . 8 1}$ & 0.13 & 0.10 \\
PEU3 & 0.27 & $\mathbf{0 . 7 8}$ & 0.14 & 0.18 \\
PEU4 & 0.19 & $\mathbf{0 . 7 8}$ & 0.18 & 0.16 \\
MOB1 & 0.23 & 0.24 & $\mathbf{0 . 7 7}$ & 0.12 \\
MOB2 & 0.09 & 0.09 & $\mathbf{0 . 8 8}$ & 0.03 \\
MOB3 & 0.16 & 0.17 & $\mathbf{0 . 8 2}$ & 0.09 \\
PU1 & 0.18 & 0.21 & 0.09 & $\mathbf{0 . 8 1}$ \\
PU2 & 0.20 & 0.11 & 0.03 & $\mathbf{0 . 7 9}$ \\
PU4 & 0.31 & 0.32 & 0.15 & $\mathbf{0 . 7 2}$ \\
\hline
\end{tabular}

Notes: CUMT, continuance usage of a mobile terminal; PEU, perceived ease of use; MOB, mobility; PU, perceived usefulness.

Table 4. Results of discriminate validity.

\begin{tabular}{lllllllll}
\hline & GEN & AGE & EDU & TOT & PU & CUMT & PEU & MOB \\
\hline GEN & NA & & & & & & & \\
AGE & 0.02 & NA & & & & & & \\
EDU & 0.07 & 0.11 & NA & & & & & \\
TOT & -0.04 & -0.02 & 0.27 & NA & & & & \\
PU & 0.12 & 0.03 & 0.01 & 0.01 & $\mathbf{0 . 7 7}$ & & & \\
CUMT & 0.13 & 0.06 & 0.02 & 0.13 & 0.54 & $\mathbf{0 . 7 9}$ & & \\
PEU & 0.12 & 0.051 & -0.02 & 0.05 & 0.50 & 0.51 & $\mathbf{0 . 7 8}$ & \\
MOB & 0.11 & 0.15 & 0.05 & 0.02 & 0.28 & 0.40 & 0.41 & $\mathbf{0 . 8 2}$ \\
\hline
\end{tabular}

Notes: CUMT, continuance usage of a mobile terminal; PEU, perceived ease of use; MOB, mobility; GEN, gender; EDU, education level; TOT, total time to use per day; PU, perceived usefulness; the bold number in the diagonal represent the square roots of AVE; value below the diagonal is correlations.

\subsection{Hypotheses Test}

To eliminate multicollinearity, this study used centered variables: PU, PEU, and mobility. We calculated the products of interaction terms and squared terms and then conducted the hypotheses test with four regression models using SPSS 19.0 [30,32]. The results are shown in Table 5. In Model 1, five control variables were added. The results show that total time of daily use and PU had significant effects on CUMT ( $\beta=0.07, p<0.05 ; \beta=0.59, p<0.01)$. In Model 2 , both PEU and mobility were added. The results show that path coefficients between PEU and CUMT as well as between mobility and 
CUMT were positive and significant $(\beta=0.28, p<0.01 ; \beta=0.16, p<0.01)$. The PEU-squared term was added in Model 3. Significant effects of PEU on CUMT, mobility on CUMT, and PEU-squared term on CUMT were observed from the results of Model 3 ( $\beta=0.36, p<0.01 ; \beta=0.17, p<0.01 ; \beta=0.17$, $\mathrm{p}<0.05, \triangle \mathrm{F}=5.36, \mathrm{p}<0.05)$. The results indicate that PEU has a curvilinear relationship with CUMT.

Table 5. Results of testing hierarchical regression models.

\begin{tabular}{|c|c|c|c|c|}
\hline & \multicolumn{4}{|c|}{ Models (CUMT) } \\
\hline & Model 1 & Model 2 & Model 3 & Model 4 \\
\hline $\mathrm{C}$ & $1.51^{* * *}$ & $2.44^{* * *}$ & $2.37^{* * *}$ & $2.50 * * *$ \\
\hline Gender & 0.10 & 0.06 & 0.07 & 0.06 \\
\hline Age & 0.04 & 0.01 & 0.01 & 0.02 \\
\hline Education level & -0.03 & -0.02 & -0.03 & -0.03 \\
\hline Total time of daily use & $0.07^{* *}$ & $0.06^{* *}$ & $0.06^{* * *}$ & $0.07^{* * *}$ \\
\hline Perceived usefulness & $0.59^{* * *}$ & $0.40^{* * *}$ & $0.40^{* * *}$ & $0.38^{* * *}$ \\
\hline PEU & & $0.28^{* * *}$ & $0.36^{* * *}$ & $0.37^{* * *}$ \\
\hline MOB & & $0.16^{* * *}$ & $0.17^{* * *}$ & $0.24^{* * *}$ \\
\hline $\mathrm{PEU} \times \mathrm{PEU}$ & & & $0.17^{* *}$ & 0.12 \\
\hline $\mathrm{PEU} \times \mathrm{MOB}$ & & & & $-0.20^{* *}$ \\
\hline $\mathrm{PEU} \times \mathrm{PEU} \times \mathrm{MOB}$ & & & & $-0.21^{* *}$ \\
\hline $\mathrm{R}^{2}$ & 0.31 & 0.41 & 0.42 & 0.44 \\
\hline Adjust $R^{2}$ & 0.30 & 0.40 & 0.41 & 0.42 \\
\hline$\triangle R^{2}$ & 0.31 & 0.10 & 0.01 & 0.02 \\
\hline $\mathrm{F}$ & $27.75^{* * *}$ & $30.45^{* * *}$ & $27.70^{* * *}$ & $23.39 * * *$ \\
\hline$\triangle \mathrm{F}$ & $27.75^{* * *}$ & $25.88^{* * *}$ & $5.36^{* *}$ & $3.98^{* *}$ \\
\hline
\end{tabular}

Notes: ${ }^{*} \mathrm{p}<0.1,{ }^{* *} \mathrm{p}<0.05,{ }^{* * *} \mathrm{p}<0.01$; CUMT, perceived ease of use; PEU, perceived ease of use; MOB, mobility.

To test $\mathrm{H} 1$ and H2, namely whether there is a U-shaped relationship under low levels of mobility and a linear relationship under high levels of mobility, we needed to obtain the estimates of the coefficients of the interaction term of mobility and PEU, called $\mathrm{M} \times \mathrm{PEU}$, and the interaction term of mobility and square of PEU, called $\mathrm{M} \times \mathrm{PEU}^{2}[30,32]$. Thus, we introduced two interaction terms, $\mathrm{M} \times \mathrm{PEU}$ and $\mathrm{M} \times \mathrm{PEU}^{2}$, into Model 4. The results show that both $\mathrm{M} \times \mathrm{PEU}$ and $\mathrm{M} \times \mathrm{PEU}^{2}$ were significant $(\beta=-0.20, \mathrm{p}<0.05 ; \beta=-0.21, \mathrm{p}<0.05)$, indicating the presence of a moderating effect. Moreover, the $\mathrm{R}^{2}$ value in Model 4 was 0.44 . Compared to Model 3, $\triangle \mathrm{R}^{2}$ was 0.02 , and the effect size $f^{2}$ was 0.03 (see Table 6), which was between 0.02 and 0.15 . Although this moderating effect is a small, it should not be ignored $[9,59]$.

Table 6. Interaction effects test.

\begin{tabular}{lcl}
\hline & $\mathbf{R}^{2}$ & f-statistics \\
\hline Model3 & 0.42 & 0.03 \\
Model4 (with a moderator) & 0.44 & \\
\hline Notes: the value of f-statistics $=\left[R^{2}\right.$ (full model)- $R^{2}$ (base model) $] /\left[1-R^{2}\right.$ (base model) $]$.
\end{tabular}

According to the significant effect of the $\mathrm{M} \times \mathrm{PEU}^{2}$ term $(\beta=-0.21, \mathrm{p}<0.05)$, the results also indicate the presence of a curvilinear relationship in the moderation process. To further test the hypotheses, we plotted the moderating effect of mobility under different levels of mobility (see Figure 2) [30,32]. As Figure 2 shows, under high levels of mobility, PEU positively and significantly influenced CUMT. However, under low levels of mobility, a low level of PEU had a negative impact on CUMT, and a high level of PEU had a positive impact on CUMT. In other words, there was a linear PEU-CUMT relationship under high levels of mobility, and there was a U-shaped PEU-CUMT relationship under low levels of mobility. The moderating effect of mobility was further verified, and both $\mathrm{H} 1$ and $\mathrm{H} 2$ were also supported. 


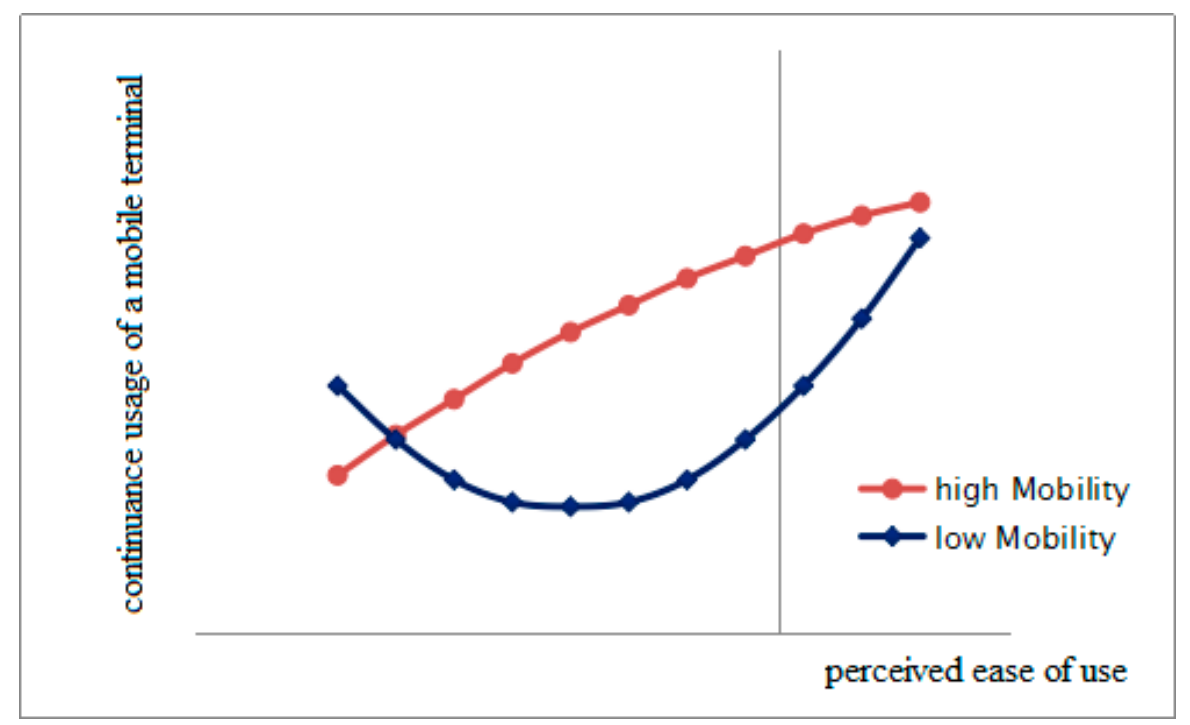

Figure 2. Moderating effect mode of mobility.

\section{Discussion}

The goal of this study was to examine the moderating effect of mobility on the relationship between PEU and CUMT to understand user usage behaviors to promote sustainable development of mobile application providers. This study explored what kinds of relationships exist under different levels of mobility based on environment-behavior relationship theory and expectation disconfirmation theory. This study has three key findings. First, this study verified that mobility moderates the PEU-CUMT relationship. In the mobile Internet context, different levels of mobility can create different usage environments, where users' different internal cognitions can be aroused and different behaviors can be found. PEU depicting user's internal beliefs can affect the behavior of using mobile terminals differently under different levels of mobility. Thus, mobility acts as a moderator of the relationship between PEU and CUMT.

The results also support the notion that there is a U-shaped relationship between PEU and CUMT under low levels of mobility. Prior studies on CU always ignored the effect of low levels of mobility on the behavior. This study indicated a change of influence of PEU on CUMT in different PEU level stages under low levels of mobility. Low levels of mobility obstruct users' cognitions of using the mobile terminal and cause negative emotion [40]. Under low levels of PEU, the divergence between expectation and actual perception also leads to user dissatisfaction. Even if PEU increases, because the dissatisfaction dominates in user internal cognition, the behavior of CUMT still decreases [41,42]. Conversely, a high level of PEU can meet user expectations and lead to user satisfaction to overcome negative emotion caused by low levels of mobility. When the positive emotion dominates, PEU turns to enhancing the behavior of CUMT to achieve the most comfortable state [40]. Therefore, different levels of PEU lead to different influences on CUMT under low levels of mobility.

Moreover, the results show that there is a linear PEU-CUMT relationship under high levels of mobility. High levels of mobility mean that a steady usage environment has been created in which the environment factor does not influence user cognition or the behavior of mobile terminal usage [40]. Under this condition, PEU can easily meet user expectations with support and help via the mobile Internet, indicating a satisfied state in user cognition. As PEU increases, user satisfaction increases, and the effect of PEU on CUMT enhances. This finding is consistent with some studies on PEU on the $\mathrm{CU}$ of mobile applications that supposed the usage environment could ensure user access to the mobile Internet easily and confirmed that users' internal beliefs have a significant effect on CU behavior [14,24]. 


\subsection{Theoretical Contributions}

The results of this study offer three theoretical contributions to the literature. First, this study contributes to the CU and mobility literature by advancing a model of CUMT that explores the relationship between PEU and CUMT. Existing research on CU based on TAM has inconsistent findings in terms of PEU on CU [21-24,60], and some studies have ignored the role of PEU without introducing this variable into their research models. The number of mobile terminal users continues to increase significantly and they are distributed in different age stages with different types of mobile terminals [47]. Meanwhile, because of the external features of mobile terminals, such as small screens, PEU is more important than before [34]. However, there are insufficient studies on the relationship between PEU and CUMT. Therefore, this study developed a model introducing PEU as an independent variable, CUMT as a dependent variable, and mobility as a moderator to examine the PEU-CUMT relationship. The empirical results showed that mobility moderates the PEU-CUMT relationship. In particular, there is a U-shaped relationship under low levels of mobility and a linear relationship under high levels of mobility. This study confirmed the importance of PEU in the behavior of CUMT and revealed the moderating process of mobility on the relationship between PEU and CUMT, extending the knowledge of $\mathrm{CU}$ and mobility in the mobile Internet context.

Second, this study enriches the curvilinear research on CU by exploring the curvilinear PEU-CUMT relationship. In many disciplines, studies of the curvilinear relationship that can provide complex explanations of some phenomena have been conducted [30-32]. However, prior works on $\mathrm{CU}$ mainly focus on linear relationships, ignoring the curvilinear relationship, and offer insufficient explanations for some phenomena. The empirical results verify the presence of a U-shaped relationship under low levels of mobility. In this study, we described the change in relationship of PEU and CUMT in different levels of PEU—namely, low levels of PEU negatively and significantly influence CUMT, and, when PEU achieves a certain level, high levels of PEU influence CUMT positively and significantly. This study offers a detailed explanation of the moderating process while exploring the behavior of CUMT, extending the score of curvilinear research in the CU field.

Third, this study extends knowledge of environment-behavior relationship theory and expectation disconfirmation theory. Previous studies on CU are based on reasoned action, such as TAM and the expectation-confirmation model $[8,14,16]$, and other theories for conducting related research. There is a lack of studies from the environmental psychology perspective that focus on the effect between environment and behavior. Based on environment-behavior relationship theory, this study elaborated on the different roles of different levels of mobility related to the behavior of CUMT. Additionally, studies of consumer behavior have always been based on expectation disconfirmation theory that focuses on repurchase or re-use behavior [41-44]. However, to our knowledge, there is a lack of studies on the curvilinear relationship in the mobile Internet context based on this theory. In addition, this study described changes in user internal cognition to explore the behavior of CUMT from the perspective of expectation disconfirmation theory. Based on those two theories, this study provides a new perspective to understand of user behavior of CUMT, extending the literature of CU and mobility.

\subsection{Practical Implications}

This study provides some practical implications for mobile application providers to facilitate their sustainable development. First, mobile application providers should understand that ease of use is a core feature of mobile applications. With the sustainable development of mobile technologies, mobile applications become more intelligent and integrated so that the use of mobile terminals becomes universal [47]. Mobile application providers should first consider providing more advantages to users, such as concise interfaces and simple interactive processes to ensure that mobile applications can substitute for traditional alternatives and attract users to sustainable use [23,34].

Second, mobile application providers should consider how to ensure ease of use, especially in low levels of mobility conditions. For example, the home page of a mobile application should be friendly enough to improve user sustainable good experience, such as quick response and utility. In addition, 
operation should be simple enough to ensure that users can successfully employ the application under limiting conditions. Moreover, because many functions of mobile applications are idle, unnecessarily taking up the memory of mobile terminals, mobile applications should be optimized by cutting down unnecessary functions to enhance the work speed and user sustainable good experience to continue to use the mobile applications [61].

Finally, mobile application providers should sustainably upgrade mobile applications with adopting new technologies and new ideas to promote mobile application providers sustainability. Mobile application providers should analyze user behavior and preferences with the big data technology. According to the results, mobile applications add new functions to attract more users to sustainably use mobile terminals, which would enhance the sustainable viability of mobile application providers.

\subsection{Limitations and Future Research}

There are some limitations to this study. First, the data were collected from young people to carry out the study. In fact, there are many elderly people who are using mobile applications through mobile terminals. The features of mobile applications have more effect on them than on the youth. Future research could collect more samples from different users, especially elderly ones, to enhance the generalizability of the study. Further, this study, based on cross-sectional survey data, could not explore the change of relationship between PEU and CUMT over time. Studies with longitudinal survey data should be conducted to compare the relationship in different stages and provide in-depth explanation of the behavior of CUMT. Moreover, we mainly focused on utilitarian factors of CUMT in this study. However, in other research context (e.g., social media and games), non-utilitarian motivations (e.g., hedonic motivations) are also predictors of behavioral intentions $[62,63]$. Therefore, future research should consider how non-utilitarian motivations might influence continued usage behavior.

\section{Conclusions}

This study focused on a phenomenon that there are different results of the relationship between PEU and CU, but there is no explanation of this phenomenon in existing studies of IS. The purpose of this study was to explore whether there is a possible curvilinear relationship between PEU and CUMT to provide an insight into the understanding of the behavior of CUMT. We advanced a model with a moderator of mobility based on the environment-behavior relationship theory and expectation disconfirmation theory. The results indicate that mobility moderated the relationship between PEU and CUMT. In addition, intriguing results were found, namely, under high levels of mobility, there was a linear PEU-CUMT relationship and, under low levels of mobility, there was a U-shaped PEU-CUMT relationship. Noteworthy contributions of the study include contributing to the literature of $\mathrm{CU}$ and mobility in the mobile Internet context, extending the curvilinear research in the CU field, and enriching knowledge of environment-behavior relationship and expectation disconfirmation theory in CU. This study suggests that future research should consider cross-sectional survey data from different users to enhance the generalizability and consider the role of non-utilitarian motivations (e.g., hedonic motivations) to predict the behavior of CUMT.

Author Contributions: Conceptualization, A.L. and J.G.; methodology, Y.S. and J.G.; collected data, X.Y. and A.L.; writing—original draft preparation, A.L.; and writing—review and editing, Y.S.

Funding: This research was funded by National Social Science Foundation of China, grant number 13BXW018.

Acknowledgments: The authors would like to acknowledge the editor's contribution and show appreciation to the reviewers for their helpful comments and recommendations.

Conflicts of Interest: The authors declare no conflict of interest. 


\section{Appendix A}

Table A1. Measurement Scales.

\begin{tabular}{|c|c|c|}
\hline Construct & Source & Items \\
\hline $\begin{array}{l}\text { Continuance usage of a mobile } \\
\text { terminal }\end{array}$ & [8] & $\begin{array}{l}\text { CUMT1: I often use a mobile terminal to access the } \\
\text { Internet. } \\
\text { CUMT2: I use a mobile terminal to access the Internet } \\
\text { many times a day. } \\
\text { CUMT3: I spend some time on a mobile terminal to access } \\
\text { the Internet every day. } \\
\text { CUMT4: I have been using a mobile terminal to access the } \\
\text { Internet for a period. }\end{array}$ \\
\hline Perceived usefulness & [18] & $\begin{array}{l}\text { PU1: I think it is very helpful for me to use a mobile } \\
\text { terminal to access the Internet. } \\
\text { PU2: I think I can address aspects of both work and life by } \\
\text { using a mobile terminal to access the Internet. } \\
\text { * PU3: I think I can more effectively contact others and } \\
\text { search for information by using a mobile terminal to access } \\
\text { the Internet } \\
\text { PU4: I think it is very useful for me to use a mobile } \\
\text { terminal to access the Internet. }\end{array}$ \\
\hline Perceived ease of use & [18] & $\begin{array}{l}\text { PEU1: I feel using a mobile terminal is very easy. } \\
\text { PEU2: I feel using a mobile terminal is very clear and } \\
\text { understandable. } \\
\text { PEU3: I feel using a mobile terminal skillfully is very easy. } \\
\text { PEU4: I feel using a mobile terminal is very easy to learn. }\end{array}$ \\
\hline Mobility & [36] & $\begin{array}{l}\text { Mob1: I can use mobile terminals to access the Internet } \\
\text { from many places, regardless of time. } \\
\text { Mob2: I can use mobile terminals to access the Internet } \\
\text { without being limited by time and space. } \\
\text { Mob3: If necessary, I can conveniently use mobile } \\
\text { terminals to access the Internet. }\end{array}$ \\
\hline
\end{tabular}

Notes: CUMT, continuance usage of a mobile terminal; PEU, perceived ease of use; MOB, mobility; PU, perceived usefulness; * deleted item.

\section{References}

1. Carter, S.; Yeo, A.C.M. Mobile apps usage by Malaysian business undergraduates and postgraduates Implications for consumer behaviour theory and marketing practice. Internet Res. 2016, 26, $733-757$. [CrossRef]

2. Chang, C.C. Exploring mobile application customer loyalty: The moderating effect of use contexts. Telecommun. Policy 2015, 39, 678-690. [CrossRef]

3. Hong, H.; Cao, M.; Wang, G.A. The effects of network externalities and herding on user satisfaction with mobile social apps. J. Electron. Commer. Res. 2017, 18, 18-31.

4. Duncan, M.; Mummery, K. Psychosocial and environmental factors associated with physical activity among city dwellers in regional Queensland. Prev. Med. 2005, 40, 363-372. [CrossRef] [PubMed]

5. Trainor, K.J.; Andzulis, J.; Rapp, A.; Agnihotri, R. Social media technology usage and customer relationship performance: A capabilities-based examination of social CRM. J. Bus. Res. 2014, 67, 1201-1208. [CrossRef]

6. Tommasetti, A.; Singer, P.; Troisi, O.; Maione, G. Extended theory of Planned Behavior (ETPB): Investigating customers' perception of restaurants' sustainability by testing a structural qquation model. Sustainability 2018, 10, 2580. [CrossRef]

7. Gogan, I.; Zhang, Z.; Matemba, E. Impacts of gratifications on consumers' emotions and continuance use intention: An empirical study of Weibo in China. Sustainability 2018, 10, 3162. [CrossRef]

8. Bhattacherjee, A. Understanding information systems continuance: An expectation confirmation model. MIS Q. 2001, 25, 351-370. [CrossRef] 
9. Limayem, M.; Cheung, C.M.K. Understanding information systems continuance: The case of Internet-based learning technologies. Inf. Manage. 2008, 45, 227-232. [CrossRef]

10. Chang, S.E.; Shen, W.C.; Liu, A.Y. Why mobile users trust smartphone social networking services? A PLS-SEM approach. J. Bus. Res. 2016, 69, 4890-4895. [CrossRef]

11. Gao, L.; Waechter, K.A.; Bai, X. Understanding consumers' continuance intention towards mobile purchase: A theoretical framework and empirical study-A case of China. Comput. Hum. Behav. 2015, 53, 249-262. [CrossRef]

12. Schierz, P.G.; Schilke, O.; Wirtz, B.W. Understanding consumer acceptance of mobile payment services: An empirical analysis. Electron. Commer. Res. Appl. 2010, 9, 209-216. [CrossRef]

13. Tam, C.; Oliveira, T. Understanding mobile banking individual performance The DeLone \& McLean model and the moderating effects of individual culture. Internet Res. 2017, 27, 538-562.

14. Thong, J.Y.L.; Hong, S.J.; Tam, K.Y. The effects of post-adoption beliefs on the expectation-confirmation model for information technology continuance. J. Hum. Comput. Stud. 2006, 64, 799-810. [CrossRef]

15. Jin, B.S.; Yoon, S.H.; Ji, Y.G. Development of a continuous usage model for the adoption and continuous usage of a smartphone. Int. J. Hum.-Comput. Interact. 2013, 29, 563-581. [CrossRef]

16. Karahanna, E.; Straub, D.W.; Chervany, N.L. Information technology adoption across time: A cross-sectional comparison of pre-adoption and post-adoption beliefs. MIS Q. 1999, 23, 183-213. [CrossRef]

17. Kim, T.; Karatepe, O.; Lee, G.; Demiral, H. Do gender and prior experience moderate the factors influencing attitude toward using social media for festival attendance? Sustainability 2018, 10, 3509. [CrossRef]

18. Davis, F.D.; Bagozzii, R.P.; Warshaw, P.R. User acceptance of computer technology: A comparison of two theoretical models. Manage. Sci. 1989, 35, 982-1003. [CrossRef]

19. Tan, G.W.H.; Ooi, K.B.; Chong, S.C.; Hew, T.S. NFC mobile credit card: The next frontier of mobile payment? Telemat. Inform. 2014, 31, 292-307. [CrossRef]

20. Upadhyay, P.; Jahanyan, S. Analyzing user perspective on the factors affecting useintention of mobile based transfer payment. Internet Res. 2016, 26, 38-56. [CrossRef]

21. Venkatesh, V;; Davis, F.D. A theoretical extension of the technology acceptance model: Four longitudinal field studies. Manage. Sci. 2000, 46, 186-204. [CrossRef]

22. Mouakket, S. Factors influencing continuance intention to use social network sites: The facebook case. Comput. Hum. Behav. 2015, 53, 102-110. [CrossRef]

23. Oghuma, A.P.; Libaque-Saenz, C.F.; Wong, S.F.; Chang, Y. An expectation-confirmation model of continuance intention to use mobile instant messaging. Telemat. Inform. 2016, 33, 34-47. [CrossRef]

24. Cho, J. The impact of post-adoption beliefs on the continued use of health apps. Int. J. Med. Inform. 2016, 87, 75-83. [CrossRef] [PubMed]

25. Yen, Y.S.; Wu, F.S. Predicting the adoption of mobile financial services: The impacts of perceived mobility and personal habit. Comput. Hum. Behav. 2016, 65, 31-42. [CrossRef]

26. Hsieh, T.C.; Chen, S.L.; Hung, M.C. Longitudinal test of ePortfolio continuous use: an empirical study on the change of students' beliefs. Behav. Inf. Technol. 2015, 34, 838-853. [CrossRef]

27. Kim, K.; Hwang, J.; Zo, H. Understanding users' continuance intention toward smartphone augmented reality applications. Inf. Dev. 2016, 32, 161-174. [CrossRef]

28. Lu, J. Are personal innovativeness and social influence critical to continue with mobile commerce? Internet Res. 2014, 24, 134-159. [CrossRef]

29. Mou, J.; Shin, D.-H.; Cohen, J.F. Tracing college students' acceptance of online health services. Int. J. Hum.-Comput. Interact. 2017, 33, 371-384. [CrossRef]

30. Baer, M.; Oldham, G.R. The curvilinear relation between experienced creative time pressure and creativity: Moderating effects of openness to experience and support for creativity. J. Appl. Psychol. 2006, 91, 963-970. [CrossRef]

31. Cortina, J.M. Interaction, nonlinearity, and multicollinearity: Implications for multiple Regression. J. Manag. 1993, 19, 915-922. [CrossRef]

32. Janssen, O. Fairness Perceptions as a Moderator in the Curvilinear Relationships between job demands, and job performance and job satisfaction. Acad. Manage. J. 2001, 44, 1039-1050.

33. Tangirala, S.; Ramanujam, R. Exploring nonlinearity in employee voice: The effects of personal control and organizational identification. Acad. Manage. J. 2008, 51, 1189-1203. [CrossRef] 
34. Yu, N.; Kong, J. User experience with web browsing on small screens: Experimental investigations of mobile-page interface design and homepage design for news websites. Inf. Sci. 2016, 330, 427-443. [CrossRef]

35. Wang, L.; Yang, J.; Yang, L. The important of enjoyment and mobility for continuance with mobile data services. In Proceedings of the Wuhan International Conference on e-Business, Wuhan, China, June 2014.

36. Nikou, S.; Bouwman, H. Ubiquitous use of mobile social network services. Telemat. Inform. 2014, 31, 422-433. [CrossRef]

37. Dovalienė, A.; Piligrimienè, Ž.; Masiulytè, A. Factors influencing customer engagement into mobile applications. Eng. Econ. 2016, 27, 205-212. [CrossRef]

38. Mallat, N.; Rossi, M.; Tuunainen, V.K.; Oorni, A. The impact of use context on mobile services acceptance: The case of mobile ticketing. Inf. Manag. 2009, 46, 190-195. [CrossRef]

39. Cabri, G.; Leonardi, L.; Zambonelli, F. Weak and strong mobility in mobile agent applications. In Proceedings of the 2nd International Conference and Exhibition on The Practical Application of Java (PA JAVA 2000), Manchester, UK, 10-14 April 2000.

40. Bell, P.A.; Greene, T.C.; Fisher, J.D.; Baum, A. Environmental Psychology 5th Edition; Renmin university of China: Beijing, Chian, 2009.

41. Anderson, R.E. Consumer dissatisfaction: the effect of disconfirmed expectancy on perceived product performance. J. Mark. Res. 1973, 10, 38-44. [CrossRef]

42. Oliver, R.L. A cognitive model of the antecedents and consequences of satisfaction decisions. J. Mark. Res. 1980, 17, 460-469. [CrossRef]

43. Oliver, R.L. Cognitive, affective, and attribute of the satisfaction response. J. Consum. Res. 1993, 20, 418-438. [CrossRef]

44. Thompson, A.G.H.; Sunoi, R. Expectations as determinants of patient satisfaction: Concepts, theory and evidence. Int. J. Qual. Health Care 1995, 7, 127-141. [CrossRef] [PubMed]

45. Joo, Y.J.; Kim, N.; Kim, N.H. Factors predicting online university students' use of a mobile learning management system (m-LMS). Educ. Technol. Res. Dev. 2016, 64, 611-630. [CrossRef]

46. Chou, M.C.; Liu, C.H. Mobile instant messengers and middle aged and elderly adults in Taiwan: Uses and gratifications. Int. J. Hum.-Comput. Interact. 2016, 32, 835-846. [CrossRef]

47. Hoehle, H.; Venkatesh, V. Moblie application usability: Conceptualization and instrument development. MIS Q. 2015, 39, 435-472. [CrossRef]

48. Son, J. The impact of initial experience and user attachment on application downloads Information-seeking and -sharing applications. Internet Res. 2017, 27, 256-276. [CrossRef]

49. Boakye, K.G. Factors influencing mobile data service (MDS) continuance intention: An empirical study. Comput. Hum. Behav. 2015, 50, 125-131. [CrossRef]

50. Chaouali, W. Once a user, always a user: Enablers and inhibitors of continuance intention of mobile social networking sites. Telemat. Inform. 2016, 33, 1022-1033. [CrossRef]

51. Witiw, C.D.; Mansouri, A.; Mathieu, F.; Nassiri, F.; Badhiwala, J.H.; Fessler, R.G. Exploring the expectation-actuality discrepancy: A systematic review of the impact of preoperative expectations on satisfaction and patient reported outcomes in spinal surgery. Neurosurg.l Rev. 2016, 1-12. [CrossRef] [PubMed]

52. Huang, G.; Korfiatis, N. Trying before buying: The moderating role of online reviews in trial attitude formation toward mobile applications. Int. J. Electron. Commer. 2015, 19, 77-111. [CrossRef]

53. Su, Y.S.; Chiang, W.L.; Lee, C.T.J.; Chang, H.C. The effect of flow experience on player loyalty in mobile game application. Comput. Hum. Behav. 2016, 63, 240-248. [CrossRef]

54. Kim, S.S.; Son, J.Y. Out of dedication or constraint? A dual model of post-adoption phenomena and its empirical test in the context of online services. MIS Q. 2009, 33, 49-70. [CrossRef]

55. Chong, A.Y.L.; Chan, F.T.S.; Ooi, K.B. Predicting consumer decisions to adopt mobile commerce: Cross country empirical examination between China and Malaysia. Decis. Support Syst. 2012, 53, 34-43. [CrossRef]

56. Ping, R.A. Estimating latent variable interactions and quadratics: The state of this art. J. Manag. 1996, 22, 163-183. [CrossRef]

57. Suvak, M.K.; Vogt, D.S.; Savarese, V.W.; King, L.A.; King, D.W. Relationship of war-zone coping strategies to long-term general life adjustment among vietnam veterans: Combat exposure as a moderator variable. Pers. Soc. Psychol. Bull. 2002, 28, 974-985. [CrossRef] 
58. Davis, D.F.; Golicic, S.L. Gaining comparative advantage in supply chain relationships: The mediating role of market-oriented IT competence. J. Acad. Mark. Sci. 2010, 38, 56-70. [CrossRef]

59. Limayem, M.; Hirt, S.G.; Cheung, C.M.K. How habit limits the predictive power of intention: The case of information systems continuance. MIS Q. 2007, 31, 705-737. [CrossRef]

60. Halilovic, S.; Cicic, M. Understanding determinants of information systems users behaviour a comparison of two models in the context of integrated accounting and budgeting software. Behav. Inf. Technol. 2013, 32, 1280-1291. [CrossRef]

61. Shin, D.H. Effect of the customer experience on satisfaction with smartphones: Assessing smart satisfaction index with partial least squares. Telecommun. Policy 2015, 39, 627-641. [CrossRef]

62. Mikalef, P.; Giannakos, M.; Pateli, A. Shopping and word-of-mouth intentions on social media. J. Theor. Appl. Electron. Commer. Res. 2013, 8, 17-34. [CrossRef]

63. Mikalef, P.; Giannakos, M.N.; Pateli, A.G. Exploring the business potential of social media: An utilitarian and hedonic motivation approach. Bled eConference. 2012. Available online: https:/ / aisel.aisnet.org/bled2012/ 21/ (accessed on 31 January 2019).

(C) 2019 by the authors. Licensee MDPI, Basel, Switzerland. This article is an open access article distributed under the terms and conditions of the Creative Commons Attribution (CC BY) license (http://creativecommons.org/licenses/by/4.0/). 